\title{
Membrane vesicles in sea water: heterogeneous DNA content and implications for viral abundance estimates
}

\author{
Steven J Biller ${ }^{1}$, Lauren D McDaniel ${ }^{2}$, Mya Breitbart ${ }^{2}$, Everett Rogers ${ }^{2}$, John H Paul ${ }^{2}$ \\ and Sallie W Chisholm ${ }^{1,3}$ \\ ${ }^{1}$ Department of Civil and Environmental Engineering, Massachusetts Institute of Technology, Cambridge, \\ MA, USA; ${ }^{2}$ College of Marine Science, University of South Florida, St Petersburg, FL, USA and ${ }^{3}$ Department of \\ Biology, Massachusetts Institute of Technology, Cambridge, MA, USA
}

\begin{abstract}
Diverse microbes release membrane-bound extracellular vesicles from their outer surfaces into the surrounding environment. Vesicles are found in numerous habitats including the oceans, where they likely have a variety of functional roles in microbial ecosystems. Extracellular vesicles are known to contain a range of biomolecules including DNA, but the frequency with which DNA is packaged in vesicles is unknown. Here, we examine the quantity and distribution of DNA associated with vesicles released from five different bacteria. The average quantity of double-stranded DNA and size distribution of DNA fragments released within vesicles varies among different taxa. Although some vesicles contain sufficient DNA to be visible following staining with the SYBR fluorescent DNA dyes typically used to enumerate viruses, this represents only a small proportion $(<0.01-1 \%)$ of vesicles. Thus DNA is packaged heterogeneously within vesicle populations, and it appears that vesicles are likely to be a minor component of SYBR-visible particles in natural sea water compared with viruses. Consistent with this hypothesis, chloroform treatment of coastal and offshore seawater samples reveals that vesicles increase epifluorescence-based particle (viral) counts by less than an order of magnitude and their impact is variable in space and time.
\end{abstract}

The ISME Journal (2017) 11, 394-404; doi:10.1038/ismej.2016.134; published online 8 November 2016

\section{Introduction}

Cells from all domains of life release extracellular vesicles (Deatherage and Cookson, 2012). These small, spherical, lipid membrane-bound structures typically range in size from $\sim 20$ to $200 \mathrm{~nm}$ diameter and provide a means for cells to interact with their environment over both spatial and temporal scales (Brown et al., 2015; Schwechheimer and Kuehn, 2015; Toyofuku et al., 2015). Vesicle release has been observed in a variety of cultured marine bacteria, ranging from the globally abundant cyanobacterium Prochlorococcus (Biller et al., 2014) to cold-adapted heterotrophic bacteria from the Antarctic (Frias et al., 2010), suggesting a role for vesicles in the ecology of marine microbial ecosystems. Field studies have confirmed that extracellular vesicles are produced by a diverse range of microbes in the marine environment, and they have been found at

Correspondence: SJ Biller or SW Chisholm, Departments of Civil and Environmental Engineering \& Biology, Massachusetts Institute of Technology, 77 Massachusetts Avenue, Bldg 48-419, Cambridge, MA 02139, USA.

E-mail: sbiller@mit.edu or chisholm@mit.edu

Received 27 May 2016; revised 12 August 2016; accepted 19 August 2016; published online 8 November 2016 concentrations of at least $10^{5}$ vesicles $\mathrm{ml}^{-1}$ in oligotrophic surface waters (Biller et al., 2014).

In Gram-negative bacteria, extracellular vesicles are derived from the outer membrane of the cell. Typically, vesicle formation is thought to begin when a region of the outer membrane separates from the peptidoglycan layer and begins to form a curved region protruding from the rest of the cell. This bulge then continues to expand until it eventually forms a complete sphere and separates from the cell (Schwechheimer and Kuehn, 2015). This 'blebbing' of the outer membrane may occur via one or more possible mechanisms, including localized reduction in membrane crosslinking, localized phospholipid or lipopolysaccharide accumulation in the outer leaflet, physical interactions among outer membrane components, or increases in membrane curvature arising from ionic interactions (McBroom et al., 2006; Schertzer and Whiteley, 2012; Rath et al., 2013; Schwechheimer et al., 2015; Roier et al., 2016). Bacteria appear to release vesicles constitutively, though stress conditions and other environmental factors can influence release rates (MacDonald and Kuehn, 2013). Bacteria growing in biofilms or under stress can also form membrane vesicles as a consequence of cell lysis, where fragments of broken 
membranes re-anneal into spherical vesicles (Turnbull et al., 2016).

Vesicles are thought to have roles in a variety of biological processes including intercellular communication and exchange, pathogenesis, nutrient acquisition, biofilm formation and cellular defense (Ellis and Kuehn, 2010; Manning and Kuehn, 2011; MacDonald and Kuehn, 2012; Brown et al., 2015; Schwechheimer and Kuehn, 2015). These diverse capabilities are a consequence of the fact that vesicles are a versatile secretion mechanism that provides cells with a means to move both hydrophobic and hydrophilic molecules through the extracellular milieu. Vesicles are comprised of lipids, proteins and other biomolecules; consistent with their mechanism of release, vesicles from Gramnegative bacteria largely contain outer membrane and periplasmic material, although cytoplasmic components are observed as well. Vesicles do not simply mimic cellular contents but can be specifically enriched or depleted in individual components (Bonnington and Kuehn, 2014).

Perhaps one of the most striking features of extracellular vesicles is that they can contain nucleic acids (Dorward et al., 1989; Valadi et al., 2007; Rumbo et al., 2011; Biller et al., 2014). DNA fragments of diverse sizes, ranging from hundreds of $\mathrm{bp}$ to $>20 \mathrm{~kb}$ have been reported in vesicles from Gram-negative bacteria, Gram-positive bacteria, archaea and eukaryotes, and include genomic, plasmid and viral DNA (Dorward and Garon, 1990; Klieve et al., 2005; Soler et al., 2008; Biller et al., 2014; Gaudin et al., 2014; Jiang et al., 2014; Grande et al., 2015; Yáñez-Mó et al., 2015). As such, vesicles can function as vehicles of horizontal gene exchange (Yaron et al., 2000; Renelli et al., 2004; Klieve et al., 2005). Shotgun sequencing of vesicleassociated DNA from ocean samples has revealed sequences from diverse bacteria, archaea and eukaryotes (Biller et al., 2014), suggesting that vesicles could be an important mechanism mediating gene transfer among marine microbes.

The observation that DNA can be found within vesicles has also raised practical concerns concerning the standard methods used by viral ecologists to measure viral abundance (Forterre et al., 2013; Soler et al., 2015). It has been suggested that membrane vesicles in natural samples may call into question viral abundance measurements (Soler et al., 2015), which are typically based on application of a fluorescent DNA-binding dye (often one of the SYBR dyes) followed by enumeration using epifluorescence microscopy or flow cytometry (Patel et al., 2007). As DNA-containing membrane vesicles are indistinguishable from viruses using these methods, the possibility exists that viral abundances may be overestimated by the presence of membrane vesicles (Soler et al., 2008, 2015; Forterre et al., 2013), although the potential magnitude of this impact has been questioned in the literature based on metagenomic sequencing of oceanic viral communities (Brum and Sullivan, 2015).
In this work, we quantify the DNA content in vesicles as well as the frequency of DNA occurrence in vesicle populations. By characterizing vesicles from a variety of marine bacteria, we addressed the following basic questions: Do all bacteria release similar amounts of DNA within vesicles? Do they release similarly-sized DNA fragments? Is DNA distributed heterogeneously or homogeneously among vesicles? Does vesicle DNA impact estimates of viral concentrations in marine ecosystems?

\section{Materials and methods}

\section{Culture conditions}

Axenic cultures of Prochlorococcus strain MED4 were grown under constant light flux (30-40 $\mathrm{mol} \mathrm{Q} \mathrm{m}^{-2} \mathrm{~s}^{-1}$ ) at $24^{\circ} \mathrm{C}$ in Pro99 media (Moore et al., 2007) prepared with $0.2 \mu \mathrm{m}$ filtered, autoclaved sea water collected from Vineyard Sound, MA. Twenty-liter cultures were supplemented with $10 \mathrm{~mm}$ (final concentration) filter-sterilized sodium bicarbonate upon inoculation and grown in polycarbonate carboys (ThermoFisher, Waltham, MA, USA) with gentle stirring (60 rpm). Myovirus P-HM2 (Sullivan et al., 2010) was prepared from $0.2 \mu \mathrm{m}$ filtered lysates of infected Prochlorococcus MED4, grown as above. Phage PM2 was prepared according to the ATCC protocol (ATCC 27025-B1) using Pseudoalteromonas espejiana BAL 31 as the host. The marine heterotrophs used in this work, Alteromonas strain MIT1002 (Biller et al., 2015), Salinicola strain MIT1003 and Thalassospira strain MIT1004, were all originally isolated from Prochlorococcus enrichment cultures by streaking onto ProMM plates (Pro99 media, as above, plus lactate, pyruvate, glycerol, acetate and Va vitamins; Berube et al., 2015) containing 1.5\% Bacto Agar (BD Difco, Franklin Lakes, NJ, USA). All strains are available upon request. Heterotroph cultures were grown in 2-10l of ProMM medium at $24^{\circ} \mathrm{C}$. Escherichia coli strain ZK126 was grown in M9 media with shaking at $37^{\circ} \mathrm{C}$.

\section{Vesicle purification}

Vesicles were purified and quantified as in Biller et al. (2014). Briefly, exponentially growing cultures were first gravity filtered through a $0.2 \mu \mathrm{m}$ capsule filter (Polycap 150TC; GE Whatman, Buckinghamshire, UK). The filtrate was then concentrated using a $100 \mathrm{kDa}$ Ultrasette tangential flow filter (Pall, Port Washington, NY, USA), re-filtered through a $0.2 \mu \mathrm{m}$ syringe filter and vesicles pelleted by ultracentrifugation at $\sim 100000 \mathrm{~g}$ (SW32Ti rotor; $32000 \mathrm{rpm}$, $1.5 \mathrm{~h}, 4^{\circ} \mathrm{C}$; Beckman Coulter, Brea, CA, USA). The vesicle pellet was next resuspended in $0.5 \mathrm{ml}$ of $45 \%$ Optiprep (Iodixanol; Sigma-Aldrich, St Louis, MO, USA) in a buffer containing $3.6 \%(\mathrm{w} / \mathrm{v}) \mathrm{NaCl}$ and $10 \mathrm{~mm}$ HEPES, $\mathrm{pH}$ 8. This was placed in the bottom of a $4 \mathrm{ml}$ UltraClear ultracentrifuge tube (Beckman Coulter) and overlaid with equal volumes of $40 \%$, 
$35 \%, 30 \%, 25 \%, 20 \%, 15 \%, 10 \%$ and 0\% Optiprep (in the same buffer background). The gradient was centrifuged at $100000 \mathrm{~g}(32000 \mathrm{rpm})$ for $6 \mathrm{~h}$ at $4^{\circ} \mathrm{C}$ in a SW60Ti rotor (Beckman Coulter). The top $1.5 \mathrm{ml}$ of gradient sample was discarded, and the next $\sim 1.5 \mathrm{ml}$ in the middle of the gradient saved. To recover vesicles, the sample was diluted at least five-fold with buffer (0.2 $\mathrm{m}$ filtered $1 \times$ phosphate-buffered saline (PBS)) and pelleted in an ultracentrifuge $\left(\sim 100000 \mathrm{~g}, 1 \mathrm{~h}, 4^{\circ} \mathrm{C}\right.$, SW60Ti rotor). The sample was washed with fresh PBS, pelleted again as above, and then resuspended in 0.02$\mu \mathrm{m}$ filtered $1 \times$ PBS. Electron microscopy (negative staining with $2 \%$ uranyl acetate) was used to confirm the contents of the vesicle samples.

\section{Vesicle quantitation}

Vesicle size distributions and concentrations were measured using a NanoSight LM10HS instrument equipped with the LM14 blue laser module and NTA software V3.1 (NanoSight/Malvern, Malvern, UK). Samples were diluted such that the average number of particles per field was between 20 and 60, per the manufacturer's guidelines. Three replicate videos were collected from each sample (by pushing additional sample through the chamber in order to acquire a different field) at a camera level of 9-10, and analyzed at a detection threshold of 1 . The sample chamber was thoroughly flushed with $18.2 \mathrm{M} \Omega \mathrm{cm}^{-1}$ water (Milli-Q; Millipore, Billerica, MA, USA) between samples, and visually examined to ensure that no particles were carried over.

Vesicle-associated DNA purification and analysis To eliminate any free DNA remaining in the sample outside of the vesicles, samples were first treated with 2 U of TURBO DNase (Invitrogen, Carlsbad, CA, USA) according to the manufacturer's instructions in a $50 \mu \mathrm{l}$ final reaction volume and incubated for $30 \mathrm{~min}$ at $37^{\circ} \mathrm{C}$. Following this, an additional $2 \mathrm{U}$ of TURBO DNase enzyme was added and incubated as before. DNase was inactivated at $75^{\circ} \mathrm{C}$ for $15 \mathrm{~min}$. Genomic DNA controls were used to confirm the effectiveness of the DNase treatment.

To lyse the vesicles, samples were incubated in GES lysis buffer (Renelli et al., 2004; $50 \mathrm{~mm}$ guanidinium thiocyanate, $1 \mathrm{~mm}$ EDTA and $0.005 \%$ (w/v) sarkosyl; final concentration) at $37^{\circ} \mathrm{C}$ for $30 \mathrm{~min}$. DNA content of lysed samples was measured by the Quant-iT PicoGreen dsDNA assay (Invitrogen), with fluorescence assayed on a Synergy2 plate reader (BioTek, Winooski, VT, USA). For determining fragment length distribution, the DNA was further purified using AMPureXP beads (Beckman Coulter) at a $2 \times$ ratio (per the manufacturer's instructions) and measured with the Bioanalyzer High Sensitivity DNA assay (Agilent, Santa Clara, CA, USA). Peaks located between the two Bioanalyzer internal standards (35 bp and $10 \mathrm{~kb}$ ) were normalized relative to the maximum peak height in that region in order to facilitate relative comparisons among samples.
Field samples

Natural seawater samples were obtained from coastal environments within Tampa Bay during June and August 2014 and from the West Florida Shelf and the Florida Keys during a cruise on the R/V Walton Smith on 4-6 January 2016. The samples were prepared for viral enumeration by $0.22 \mu \mathrm{m}$ filtration using Sterivex filters (Millipore) for cruise samples or Millex cartridge filters (Millipore) to remove bacterial cells and all larger organisms. Samples were divided in half to provide a chloroform treatment and a control sample. Chloroform treatment was conducted by mixing the filtered sea water with an equal volume of chloroform, followed by thorough mixing and centrifugation in a phase lock gel tube (5 Prime, Gaithersburg, MD, USA) according to the manufacturer's instructions. The aqueous layer was recovered and used for further analyses.

\section{Enumeration of SYBR-visible particles}

Epifluorescence microscopy-based particle counts were carried out using the SYBR Gold staining method according to standard protocols (Noble and Fuhrman, 1998; Patel et al., 2007). In brief, the samples were filtered onto a $25 \mathrm{~mm}$ diameter, $0.02 \mu \mathrm{m}$ Anodisc filter (GE Whatman) and the filter floated on a drop of diluted $(2.5 \times)$ SYBR Gold stain (Molecular Probes/ThermoFisher, Waltham, MA, USA) and incubated for 9-15 min in the dark. The backs of the filters were dried via Kimwipe or vacuum to remove excess stain. The filters were mounted on a glass microscope slide and covered with a coverslip with $28 \mu \mathrm{l}$ of antifade mounting solution (0.1\% phenylenediamine in 50\% PBS/50\% glycerol) and stored in the dark at $-20^{\circ} \mathrm{C}$ until counted. The samples were viewed and enumerated under blue excitation using $\times 1000$ magnification with either a Zeiss Axioskop2 (Carl Zeiss, Oberkochen, Germany; cultured samples) or an Olympus BX60 microscope (Olympus, Tokyo, Japan; field samples), both fitted with a counting grid. A minimum of 400 particles or 20 fields was counted per sample.

For flow cytometry, $1 \mathrm{ml}$ replicate samples of treatments and controls were placed in labeled cryovials, fixed with glutaraldehyde to $0.5 \%$ final concentration, incubated at $4^{\circ} \mathrm{C}$ for $10-30 \mathrm{~min}$, then snap frozen in liquid nitrogen and stored at $-80^{\circ} \mathrm{C}$ until analysis by flow cytometry. For analysis the samples were thawed and diluted in TE buffer $(\mathrm{pH}$ 8.0) as needed to obtain an optimal counting event rate of 100-1000 events per second. The samples were stained with SYBR Green I (Molecular Probes/ ThermoFisher) to a final concentration of $0.5 \times$ of the manufacturer's stock solution and incubated at $80^{\circ} \mathrm{C}$ in a water bath for $10 \mathrm{~min}$ using $1 \mu \mathrm{m}$ diameter fluorescent beads (Polysciences, Warminster, PA, USA) as an internal standard, according to standard protocols (Brussaard et al., 2000; Brussaard, 2004, 2009). The samples were analyzed on a FACSCalibur flow cytometer (Becton Dickenson, Franklin Lakes, NJ, USA) equipped with an air-cooled laser at $488 \mathrm{~nm}$ and a 
standard filter setup using SYBR fluorescence as the trigger. Data were acquired and processed with Cell Quest Pro software (Becton Dickenson). Flow rates were determined at both the beginning and end of each day the machine was used, and the average value for that day was used for calculating particles per ml. Abundances were based on a minimum of three technical replicates on each of two replicate samples.

\section{Data analysis}

All statistical analyses were conducted in either Microsoft Excel (Microsoft, Redmond, WA, USA) or in R V3.2.2 ( $\mathrm{R}$ Core Team, 2015). Figures were generated using ggplot2 (Wickham, 2009) and Ocean Data View (Schlitzer, 2016). The Salinicola MIT1003 and Thalassospira MIT1004 genomes were sequenced as previously described (Biller et al., 2015) and assembled with the SPAdes assembler (Bankevich et al., 2012; V3.5.0) using the following options: - $\mathrm{k}$ 21,33,55,77 -careful -only-assembler and retaining only contigs $>500 \mathrm{bp}$. Taxonomic identities of these strains were determined by the RDP classifier (Wang et al., 2007), and the draft genomes have been deposited in the NCBI database under accessions MCAP00000000 (MIT1003) and MCAO00000000 (MIT1004). The Alteromonas (NCBI accession JXRW01000000), Salinicola and Thalassospira genomes were screened for gene transfer agents (GTAs; based on homology to Rhodobacter capsulatus proteins RCAP_rcc01683 and RCAP_rcc01698) and the Pseudomonas aeruginosa Lys endolysin (protein PA0629) using BLAST+ (Camacho et al., 2009) with an e-value cutoff $<1 \times 10^{-4}$.

\section{Results}

Vesicle-associated DNA content varies among microbial taxa

We first examined the size distribution of DNA associated with vesicles released from three marine heterotrophs, Alteromonas, Salinicola and
Thalassospira. Each of these strains released DNA fragments with a unique size distribution between $35 \mathrm{bp}$ and $10 \mathrm{~kb}$ (Figure 1). For example, Salinicola vesicles were associated with fragments mostly $<1000 \mathrm{bp}$, whereas DNA segments associated with Alteromonas vesicles were notably longer. Thalassospira vesicle DNA fragments were broadly distributed between the $35 \mathrm{bp}$ and $10 \mathrm{~kb}$ range examined, and contained fragments $>10 \mathrm{~kb}$ as well. The sizes of vesicle DNA from each of these three strains exhibited a less discrete fragment size distribution than that previously observed from Prochlorococcus (Figure 1; Biller et al., 2014). Attempts to determine the fragment size distribution from E. coli have not been successful to date, for reasons that are unclear. Although the differences in the DNA content of vesicles produced by Prochlorococcus versus heterotrophs could be partly due to sampling effects, these data suggest that the processes that generate the DNA fragments exported in vesicles do not function the same in all bacteria.

Given the observed size range of vesicle-associated DNA, we wondered how many fragments might be packaged within each vesicle. To this end, we measured the average amount of double-stranded DNA present in each vesicle using standard fluorometric approaches. When considered on a bulk average basis, each individual vesicle contains on the order of zeptograms $\left(10^{-21} \mathrm{~g}\right)$ of DNA-equivalent to tens to hundreds of basepairs of DNA (Table 1). Given that many, if not most, of the DNA fragments observed in these vesicle populations are typically much longer than this (Figure 1), we conclude that DNA is not uniformly incorporated into bacterial extracellular vesicles. Average vesicle DNA content from these different strains was positively correlated with vesicle diameter (Table 1); however, given the broad distribution of vesicle sizes (Supplementary Figure S1) and DNA fragment lengths (Figure 1), it is not yet clear if longer fragments, or greater quantities of DNA, are necessarily associated with larger vesicles.

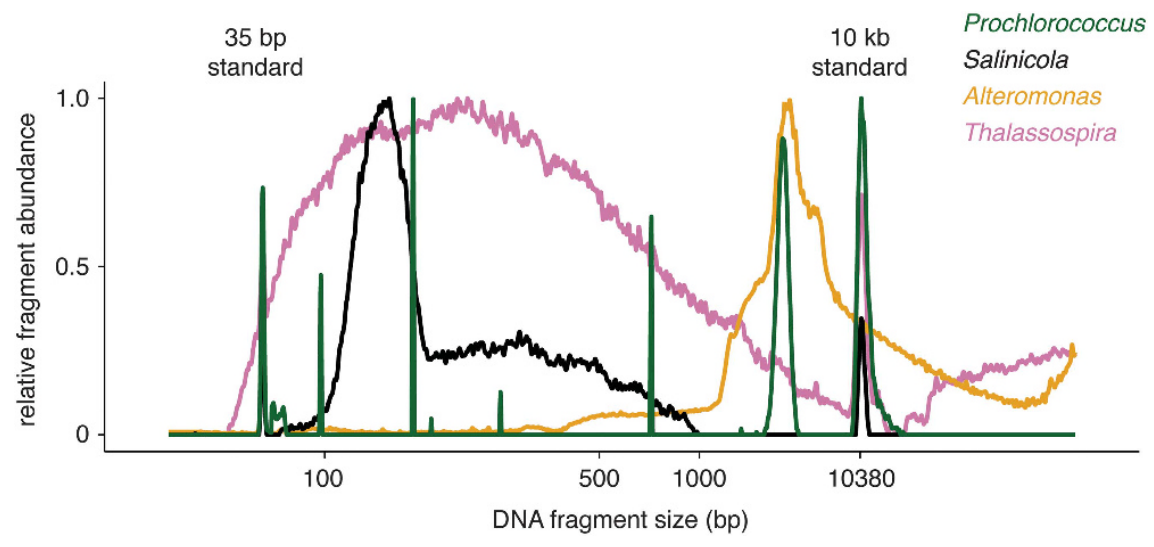

Figure 1 Size distribution of DNA associated with extracellular vesicles from marine bacteria. Fragment size distribution of doublestranded DNA extracted from extracellular vesicles of cultured isolates of Salinicola (black), Alteromonas (orange) and Thalassospira (violet) compared with data for Prochlorococcus (green; Biller et al., 2014). Peaks for all strains at 35 bp and 10 kb are Bioanalyzer internal standards. 
Table 1 Size and population average double-stranded DNA content of vesicles from cultured bacteria

\begin{tabular}{lccc}
\hline Strain & dsDNA/vesicle (ng) & $\begin{array}{c}\text { dsDNA/ } \\
\text { vesicle } \\
(\mathrm{bp})\end{array}$ & $\begin{array}{c}\text { Mode vesicle } \\
\text { diameter } \\
(\mathrm{nm})\end{array}$ \\
\hline E. coli & $1.9( \pm 2.6) \times 10^{-11}$ & 17 & $80( \pm 3)$ \\
Prochlorococcus & $3.1( \pm 2.4) \times 10^{-11}$ & 28 & $92( \pm 9)$ \\
Salinicola & $1.6( \pm 2.2) \times 10^{-10}$ & 149 & $126( \pm 9)$ \\
Alteromonas & $1.9( \pm 2.2) \times 10^{-10}$ & 174 & $117( \pm 11)$ \\
Thalassospira & $5.1( \pm 3.8) \times 10^{-10}$ & 473 & $126( \pm 7)$ \\
\hline
\end{tabular}

Abbreviation: dsDNA, double-stranded DNA.

Mean DNA length was calculated assuming an average mass of $1.08 \times 10^{-12} \mathrm{ng}$ per bp. Values indicate the mean \pm s.d. from two biological replicates.

DNA is packaged heterogeneously within bacterial extracellular vesicles

To more directly test the hypothesis that DNA is not uniformly distributed among individual vesicles, we measured the fraction of vesicles visible by staining with the DNA-binding dye SYBR Gold using epifluorescence microscopy, and compared this number with the total vesicle counts determined by nanoparticle tracking analysis. Only a small fraction of vesicles $(<1 \%)$ from all of the bacterial strains tested were visible by SYBR staining (Figure 2; Supplementary Figure S2). As only vesicles containing a relatively large amount of DNA ( $>9 \mathrm{~kb}$ ) are likely to be visible by SYBR epifluorescence (Tomaru and Nagasaki, 2007), any vesicles containing only short fragments would be missed in these counts; thus although these findings are consistent with heterogeneity in the contents of bacterial vesicles, these values represent only a lower bound estimate for the fraction of vesicles containing any DNA. Together, these results support the hypothesis that the DNA content of individual extracellular vesicles is variable.

\section{Contribution of extracellular vesicles to}

epifluorescence-based viral abundance estimates

Our finding that staining and quantifying vesicles from cultured bacteria using epifluorescence microscopy protocols identical to those commonly used to measure viral abundances in sea water resulted in the detection of $<1 \%$ of the vesicles (Figure 2) challenges recent hypotheses that marine viral abundance may be grossly overestimated due to the presence of membrane vesicles (Soler et al., 2015). Given estimates of vesicle concentrations in the upper ocean of $10^{5}-10^{6} \mathrm{ml}^{-1}$ for oligotrophic and coastal stations, respectively (Biller et al., 2014), these measurements suggest that $<1 \%$ of these vesicles, or $10^{3}-10^{4} \mathrm{ml}^{-1}$, might be visible when using standard epifluorescence protocols for quantifying viruses (or technically, virus-like particles). As virus concentrations in the surface ocean are typically on the order of $10^{6}-10^{7} \mathrm{ml}^{-1}$ (Parsons et al., 2012; Wigington et al., 2016), this implies that extracellular vesicles might represent $<0.1 \%$ error

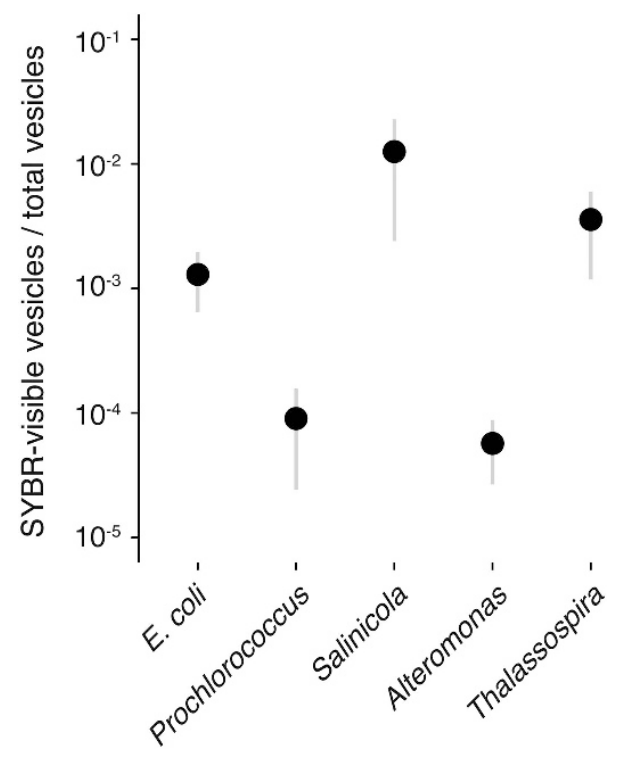

Figure 2 Quantitative analysis of vesicles visible by epifluorescence microscopy. SYBR Gold-visible particle concentrations were determined from cultures of the indicated bacteria and compared with the total vesicle concentration determined by nanoparticle tracking analysis. Values indicate mean \pm s.d. of three biological replicates.

in these values. Obviously this value could easily vary as a function of bacterial community composition and the potential for other bacterial groups to release SYBR-visible vesicles at much greater frequencies than those sampled here.

To better determine the impact of vesicles on viral counts in the field, we measured the potential contribution of vesicles to epifluorescence counts in several natural seawater samples. Although physical attributes such as size and density have been used to physically separate vesicles from some types of viruses present in marine samples, it is difficult to isolate vesicles away from filamentous and other viruses (and possibly GTAs-host-encoded viral-like particles that contain cellular DNA) based on these traits alone (Biller et al., 2014). To discriminate between vesicles and viruses, we took advantage of the fact that their lipid membranes make vesicles sensitive to disruption with chloroform (Supplementary Figure S3; Forterre et al., 2013). We examined seawater samples collected from coastal sites in Florida and multiple locations in the Gulf of Mexico (Figure 3a). Removing vesicles via chloroform treatment had no significant impact on epifluorescence particle counts from samples collected at the two coastal sites at one sampling date. However, another sample collected on a different day at one of these locations revealed a $\sim 7 \times$ decrease in particle counts following chloroform treatment (Figure 3b), suggesting temporal variability in the potential contribution of SYBR-visible vesicles or lipid-containing viruses. Epifluorescence virus-like particle counts, with and without chloroform treatment, were also obtained from cruise samples from the West Florida Shelf and Florida Keys. All samples collected on this 

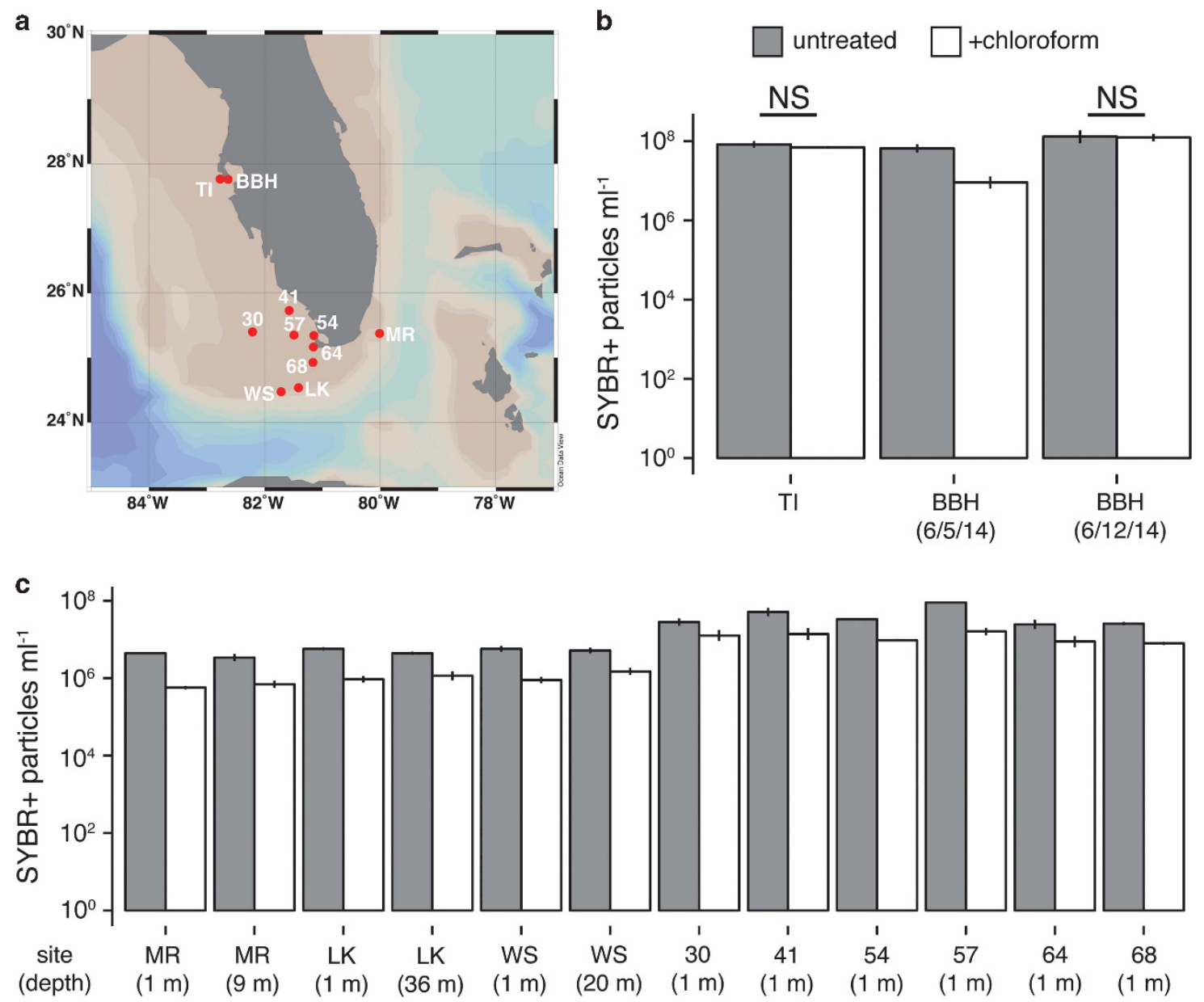

Figure 3 Bounding the potential contribution of vesicles to estimates of viral abundance in marine samples based on SYBR staining. (a) Field sampling locations. (b) Impact of chloroform treatment on SYBR-based particle counts from three coastal sites. NS=not statistically significant $(P>0.05$, two-tailed $t$-test); the Bayboro Harbor (BBH) sample collected on 06 May 2014 exhibited a significant difference $(P<0.05$, two-tailed $t$-test). (c) Impact of chloroform treatment on samples from the Gulf of Mexico. All samples exhibited a statistically significant difference in particle abundance between untreated and chloroform-treated samples $(P<0.05$, two-tailed $t$-test). Data in (b) and (c) represent the mean \pm s.d. of two replicates.

cruise yielded significantly lower viral counts following chloroform treatment (Figure 3c), with the magnitude of this effect varying between $\sim 2 \times$ and $\sim 8 \times$. These results suggest that DNA-containing bacterial vesicles contribute, at most, less than an order-of-magnitude error to viral counts; it also implies that the lower bound of viral (or GTA) abundances in these samples was $12-50 \%$ of the SYBR-visible particle count.

Although many marine phages are not affected by chloroform, some phages such as the membranecontaining aquatic phages in the family Corticoviridae (that is, phage PM2) will be at least partially destroyed by this treatment (Supplementary Figure S3; Espejo and Canelo, 1968; Krupovic and Bamford, 2007; Poranen et al., 2015). In fact, some early estimates have suggested that up to $30 \%$ of tailed phages are chloroform sensitive based on loss of infectivity (Ackermann and DuBow, 1987), yet it is unknown if this would destroy the particle beyond recognition by epifluorescence-based methods. In addition, many viruses infecting archaea (for example, Pietilä et al., 2009) and eukaryotes (for example, Martínez Martínez et al., 2015) contain lipid membranes, suggesting that lipid-containing viruses may be more prevalent in the marine environment than previously thought. As chloroform treatment may eliminate lipid-containing viruses, it is not a perfect method for distinguishing vesicles from viruses. Nonetheless, comparing SYBR counts from environmental samples before and after chloroform treatment establishes an upper bound on the potential contribution of vesicles to epifluorescence-based viral counts. Collectively, the low frequency of epifluorescence-visible vesicles produced by cultured isolates (Figure 2), combined with the relatively small decrease in SYBRstained particles from natural marine samples upon chloroform treatment, leads us to propose that vesicles are not likely to have a notable impact on estimates of viral abundance in the environment.

\section{Discussion}

The heterogeneity of vesicle contents is becoming increasingly apparent in studies of eukaryotic 
exosomes, which have been shown to differ in their morphological, proteomic and chemical composition (Höög and Lötvall, 2015; Smith et al., 2015; Koliha et al., 2016; Kowal et al., 2016). The results presented here demonstrate that DNA is heterogeneously incorporated into bacterial vesicles, supporting the notion that extracellular vesicle populations are comprised of distinct subpopulations with unique compositions (Schwechheimer and Kuehn, 2015). Thus the distribution of contents among bacterial vesicles needs to be considered, as their ability to carry out a particular ecological function may depend on the relative abundance of vesicles containing the required components within the population.

The mechanism through which DNA fragments are first generated and then integrated into membrane vesicles remains unclear. There is long-standing evidence that DNA can be incorporated into vesicles from the periplasm (Renelli et al., 2004), though precisely how the DNA could move across the inner membrane is not known. An alternate route for DNA incorporation into vesicles comes from the observation of a subpopulation of vesicles, termed 'outerinner membrane vesicles', which contain both the outer and inner membranes instead of just outer membrane material (Pérez-Cruz et al., 2013). If the cell is able to pinch off both the outer and inner membranes to form vesicles, there would be a clear topological route for incorporating DNA from the cytoplasm into extracellular vesicles (Pérez-Cruz et al., 2015). Double-stranded DNA has been found within outer-inner membrane vesicles, which make up only a small proportion $(<1.2 \%)$ of membrane vesicles from some Gram-negative bacteria (PérezCruz et al., 2015). Although those findings are consistent with the heterogeneity of DNAcontaining vesicles observed here (Figure 2), we do not know what fraction of SYBR-visible vesicles might have been outer-inner membrane vesicles. Another potential mechanism for incorporating DNA into vesicles is that this occurs extracellularly (Renelli et al., 2004). For example, P. aeruginosa vesicles can be formed as a consequence of cell lysis, wherein fragments of broken membranes re-anneal into vesicles and, consequently, trap DNA and other cytoplasmic material released by the lysed cells (Turnbull et al., 2016). This mechanism is associated with the activity of a phage endolysin, which is required for vesicle formation under biofilm and stressed conditions, though the endolysin does not impact vesicle release during normal planktonic growth (Turnbull et al., 2016). Although the marine strains studied here have no obvious homolog to that particular $P$. aeruginosa endolysin and were examined during normal growth conditions, it is possible that at least some of the DNA-containing vesicles observed here were derived from a subpopulation of lysing cells. It will be interesting, particularly from the perspective of improving our insight into vesicle formation and packaging mechanisms, for future studies to determine whether larger fragments of DNA are specifically found in larger vesicles. Viral capsid sizes, for example, are also positively correlated with DNA content (Jover et al., 2014), but viral and vesicle packaging mechanisms are likely to be quite different. Much work remains to determine the mechanism(s) by which different subpopulations of vesicles are formed and become associated with DNA.

The observed species-level differences in both the size and amount of DNA fragments in vesicles have important implications for the potential of vesicles to act as agents of horizontal gene transfer. Although bacteria can take up short pieces of DNA and recombine them into their genomes (OverballePetersen et al., 2013), a microbe which releases primarily shorter fragments within vesicles may be less likely to deliver complete genes. The disparities in vesicle-associated DNA fragment lengths found among strains is striking, and future studies should investigate the mechanism by which these DNA fragments are generated and the additional factors that may influence this process. Such differences in DNA fragment length distributions among microbes also have implications for the interpretation of metagenomic data collected from natural vesicle populations, as the relative amount of DNA contained within a vesicle population may not necessarily reflect the relative number of vesicles released from each strain. Vesicle DNA content may also vary under different physiological conditions, as vesicles from biofilm-associated Helicobacter pylori cells have been found to contain more DNA than those released by planktonic cells (Grande et al., 2015).

Although extracellular vesicles that contain larger DNA fragments clearly can be detected using the epifluorescence approaches that are frequently used to enumerate viruses in the field (Forterre et al., 2013), they are not likely to have systematically inflated those measurements to a notable degree. Errors in viral counts arise from a wide variety of factors, ranging from differences in sample handling, slide preparation equipment, method of visualization (that is, microscopy versus flow cytometry) and variation in counting inherent to different individuals. Thus while vesicles may contribute some amount of error, the magnitude of this error must be considered in the context of other error sources. In addition to vesicles, GTAs are widespread in the marine environment (Biers et al., 2008; McDaniel et al., 2010; Lang et al., 2012) and may inflate viral counts (Forterre et al., 2013). However, GTAs are generally smaller and contain less nucleic acid than bacteriophages (Lang and Beatty, 2010; Lang et al., 2012) making them likely to be missed by standard methods. In addition, RNA viruses and singlestranded DNA viruses, which are being identified in the oceans with increasing frequency (Culley et al., 2006; Labonté and Suttle, 2013; Steward et al., 2013; Hopkins et al., 2014; Rosario et al., 2015), may not be visible by epifluorescence methods due to 
their small genome sizes (Tomaru and Nagasaki, 2007) and/or poor staining by commonly used dyes (Holmfeldt et al., 2012); this would lead to an underestimation of viral abundance using standard methods. Finally, epifluorescence enumeration methods can also be biased through the misidentification of small bacteria as viruses (overestimating viral abundance; Stockner et al., 1990) or due to the removal of large viruses (for example, Van Etten and Meints, 1999; Fischer et al., 2010) during sample filtration or their misclassification as bacteria (leading to an underestimation of viral abundance). In light of all these factors, determinations of viral abundance (often more appropriately referred to as counts of virus-like particles) should be considered estimates-likely within an order of magnitude of the actual value, but with several layers of uncertainty.

The relationships and interactions between viruses and vesicles constitute an interesting and open set of questions. Vesicles may have important effects on marine viral ecology by acting as defense agents (cellular decoys) or through serving as vehicles for moving DNA and other molecules between cells, which could in turn alter host sensitivity. The dynamics of these ecological interactions will be influenced by the ratio of viruses to vesicles in a given location, but measuring the relative abundances of vesicles and viruseslet alone those impacting a specific group of cellsremains technically challenging. Vesicles and many viruses are similarly sized, making them difficult to physically separate using standard techniques in biological oceanography and marine biology. In some cases, they can also have similar buoyant densities, further complicating efforts to separate them. There are, however, important distinguishing features. By negative staining and transmission electron microscopy, phages typically have angular, structured features whereas membrane vesicles have a distinct spherical and nearly amorphous appearance. An example of this is the tailless viral particles observed throughout the oceans by Brum et al. (2013), which are clearly distinguishable from membrane vesicles (Kadurugamuwa and Beveridge, 1995; Kesty and Kuehn, 2004; Biller et al., 2014). Interestingly, during the development and validation of DNA staining and epifluorescence microscopybased counting techniques for viruses, these methods yielded counts 1-7 $\times$ greater than transmission electron microscopy counts (for example, Hara et al., 1991; Hennes and Suttle, 1995; Proctor, 1997; Weinbauer and Suttle, 1997). In particular, epifluorescence counts using SYBR dyes were an average of $1.5 \times$ higher than those obtained through transmission electron microscopy (Noble and Fuhrman, 1998; Marie et al., 1999; Chen et al., 2001). These differences are similar to the decreases in viral abundance observed in this study following chloroform treatment, again putting the impact of membrane vesicles on epifluorescence determination of viral abundance in perspective.
Similarly, much remains to be elucidated concerning the contribution of viral DNA to vesicle metagenomes-as well as of vesicle DNA to bacterial and viral metagenomes. Although there is almost certainly 'bona fide' viral contamination in vesicle samples from the field (Soler et al., 2015), evaluating the magnitude of this issue is complicated by the release of viral DNA and other mobile elements within vesicles (Yaron et al., 2000; Renelli et al., 2004; Soler et al., 2008; Gaudin et al., 2014), as well as technical considerations including the potential for preferential amplification of single-stranded DNA phage sequences during some library preparation protocols (Kim and Bae, 2011; Szekely and Breitbart, 2016). Likewise, vesicles and GTAs may serve as a source of bacterial sequences in viral metagenomes (Roux et al., 2013), but current methods cannot definitively distinguish these contributions from true phage auxiliary metabolic genes (Hurwitz and U'Ren, 2016). All of the caveats and considerations discussed here reinforce the need for further method development to improve the ability to enumerate viruses in field samples and to discriminate among the many small colloidal particles of biological origin present in the oceans.

\section{Conflict of Interest}

The authors declare no conflict of interest.

\section{Acknowledgements}

We thank Katya Frois-Moniz, Phil Arevalo, Madeline Williams and Keven Dooley for laboratory assistance, and Stefan Bertilsson for isolating the Salinicola and Thalassospira strains. E. coli was a gift from Christopher Corzett, and phage PM2 and its host strain were kindly provided by Dennis Bamford. Tony Greco helped with electron microscopy, and Anni Djurhuus and Enrique Montes collected field samples from the West Florida Shelf and Florida Keys. SJB and SWC were supported by grants to SWC from the National Science Foundation (OCE-1356460) and the Simons Foundation (grant 337262, and SCOPE Award ID 329108 to SWC). This work was also supported by grants to MB from the National Science Foundation (IOS-1456301) and NASA grant NNX14AP62A 'National Marine Sanctuaries as Sentinel Sites for a Demonstration Marine Biodiversity Observation Network (MBON)' funded under the National Ocean Partnership Program (NOPP RFP NOAA-NOS-IOOS-2014-2003803 in partnership between NOAA, BOEM and NASA). This is a contribution of the Simons Collaboration on Ocean Processes and Ecology (SCOPE).

\section{References}

Ackermann H-W, DuBow MS. (1987). Viruses of Prokaryotes. CRC Press: Boca Raton, FL, USA.

Bankevich A, Nurk S, Antipov D, Gurevich AA, Dvorkin M, Kulikov AS et al. (2012). SPAdes: a new genome 
assembly algorithm and its applications to single-cell sequencing. J Comput Biol 19: 1-23.

Berube PM, Biller SJ, Kent AG, Berta-Thompson JW, Roggensack SE, Roache-Johnson KH et al. (2015). Physiology and evolution of nitrate acquisition in Prochlorococcus. ISME J 9: 1195-1207.

Biers EJ, Wang K, Pennington C, Belas R, Chen F, Moran MA. (2008). Occurrence and expression of gene transfer agent genes in marine bacterioplankton. Appl Environ Microbiol 74: 2933-2939.

Biller SJ, Coe A, Martin-Cuadrado A-B, Chisholm SW. (2015). Draft genome sequence of Alteromonas macleodii strain MIT1002, isolated from an enrichment culture of the marine cyanobacterium Prochlorococcus. Genome Announc 3: e00967-15.

Biller SJ, Schubotz F, Roggensack SE, Thompson AW, Summons RE, Chisholm SW. (2014). Bacterial vesicles in marine ecosystems. Science 343: 183-186.

Bonnington KE, Kuehn MJ. (2014). Protein selection and export via outer membrane vesicles. Biochim Biophys Acta 1843: 1612-1619.

Brown L, Wolf JM, Prados-Rosales R, Casadevall A. (2015). Through the wall: extracellular vesicles in Grampositive bacteria, mycobacteria and fungi. Nat Rev Microbiol 13: 620-630.

Brum JR, Schenck RO, Sullivan MB. (2013). Global morphological analysis of marine viruses shows minimal regional variation and dominance of non-tailed viruses. ISME J 7: 1738-1751.

Brum JR, Sullivan MB. (2015). Rising to the challenge: accelerated pace of discovery transforms marine virology. Nat Rev Microbiol 13: 147-159.

Brussaard CP, Marie D, Bratbak G. (2000). Flow cytometric detection of viruses. J Virol Methods 85: 175-182.

Brussaard CPD. (2009). Enumeration of bacteriophages using flow cytometry. Methods Mol Biol 501: 97-111.

Brussaard CPD. (2004). Optimization of procedures for counting viruses by flow cytometry. Appl Environ Microbiol 70: 1506-1513.

Camacho C, Coulouris G, Avagyan V, Ma N, Papadopoulos J, Bealer K et al. (2009). BLAST+: architecture and applications. BMC Bioinformatics 10: 421.

Chen F, Lu J-R, Binder BJ, Liu Y-C, Hodson RE. (2001). Application of digital image analysis and flow cytometry to enumerate marine viruses stained with SYBR Gold. Appl Environ Microbiol 67: 539-545.

Culley AI, Lang AS, Suttle CA. (2006). Metagenomic analysis of coastal RNA virus communities. Science 312: 1795-1798.

Deatherage BL, Cookson BT. (2012). Membrane vesicle release in bacteria, eukaryotes, and archaea: a conserved yet underappreciated aspect of microbial life. Infect Immun 80: 1948-1957.

Dorward DW, Garon CF. (1990). DNA is packaged within membrane-derived vesicles of Gram-negative but not Gram-positive bacteria. Appl Environ Microbiol 56: 1960-1962.

Dorward DW, Garon CF, Judd RC. (1989). Export and intercellular transfer of DNA via membrane blebs of Neisseria gonorrhoeae. J Bacteriol 171: 2499-2505.

Ellis TN, Kuehn MJ. (2010). Virulence and immunomodulatory roles of bacterial outer membrane vesicles. Microbiol Mol Biol Rev 74: 81-94.

Espejo RT, Canelo ES. (1968). Properties and characterization of the host bacterium of bacteriophage PM2. J Bacteriol 95: 1887-1891.
Fischer MG, Allen MJ, Wilson WH, Suttle CA. (2010). Giant virus with a remarkable complement of genes infects marine zooplankton. Proc Natl Acad Sci USA 107: 19508-19513.

Forterre P, Soler N, Krupovic M, Marguet E, Ackermann H-W. (2013). Fake virus particles generated by fluorescence microscopy. Trends Microbiol 21: 1-5.

Frias A, Manresa A, de Oliveira E, López-Iglesias C, Mercade E. (2010). Membrane vesicles: a common feature in the extracellular matter of cold-adapted antarctic bacteria. Microbial Ecol 59: 476-486.

Gaudin M, Krupovic M, Marguet E, Gauliard E, CvirkaiteKrupovic V, Le Cam E et al. (2014). Extracellular membrane vesicles harbouring viral genomes. Environ Microbiol 16: 1167-1175.

Grande R, Di Marcantonio MC, Robuffo I, Pompilio A, Celia C, Di Marzio L et al. (2015). Helicobacter pylori ATCC 43629/NCTC 11639 outer membrane vesicles (OMVs) from biofilm and planktonic phase associated with extracellular DNA (eDNA). Front Microbiol 6: 1114-11.

Hara S, Terauchi K, Koike I. (1991). Abundance of viruses in marine waters: assessment by epifluorescence and transmission electron microscopy. Appl Environ Microbiol 57: 2731-2734.

Hennes KP, Suttle CA. (1995). Direct counts of viruses in natural waters and laboratory cultures by epifluorescence microscopy. Limnol Oceanogr 40: 1050-1055.

Holmfeldt K, Odić D, Sullivan MB, Middelboe M, Riemann L. (2012). Cultivated single-stranded DNA phages that infect marine Bacteroidetes prove difficult to detect with DNA-binding stains. Appl Environ Microbiol 78: 892-894.

Hopkins M, Kailasan S, Cohen A, Roux S, Tucker KP, Shevenell A et al. (2014). Diversity of environmental single-stranded DNA phages revealed by PCR amplification of the partial major capsid protein. ISME J 8: 2093-2103.

Höög JL, Lötvall J. (2015). Diversity of extracellular vesicles in human ejaculates revealed by cryo-electron microscopy. J Extracell Vesicles 4: 28680.

Hurwitz BL, U’Ren JM. (2016). Viral metabolic reprogramming in marine ecosystems. Curr Opin Microbiol 31: 161-168.

Jiang Y, Kong Q, Roland KL, Curtiss R III. (2014). Membrane vesicles of Clostridium perfringens type A strains induce innate and adaptive immunity. Int J Med Microbiol 304: 431-443.

Jover LF, Effler TC, Buchan A, Wilhelm SW, Weitz JS. (2014). The elemental composition of virus particles: implications for marine biogeochemical cycles. Nat Rev Microbiol 12: 519-528.

Kadurugamuwa JL, Beveridge TJ. (1995). Virulence factors are released from Pseudomonas aeruginosa in association with membrane vesicles during normal growth and exposure to gentamicin: a novel mechanism of enzyme secretion. J Bacteriol 177: 3998-4008.

Kesty NC, Kuehn MJ. (2004). Incorporation of heterologous outer membrane and periplasmic proteins into Escherichia coli outer membrane vesicles. J Biol Chem 279: 2069-2076.

Kim K-H, Bae J-W. (2011). Amplification methods bias metagenomic libraries of uncultured single-stranded and double-stranded DNA viruses. Appl Environ Microbiol 77: 7663-7668.

Klieve AV, Yokoyama MT, Forster RJ, Ouwerkerk D, Bain PA, Mawhinney EL. (2005). Naturally occurring DNA transfer 
system associated with membrane vesicles in cellulolytic Ruminococcus spp. of ruminal origin. Appl Environ Microbiol 71: 4248-4253.

Koliha N, Wiencek Y, Heider U, Jüngst C, Kladt N, Krauthäuser S et al. (2016). A novel multiplex beadbased platform highlights the diversity of extracellular vesicles. J Extracell Vesicles 5: 29975.

Kowal J, Arras G, Colombo M, Jouve M, Morath JP, Primdal-Bengtson B et al. (2016). Proteomic comparison defines novel markers to characterize heterogeneous populations of extracellular vesicle subtypes. Proc Natl Acad Sci USA 113: E968-E977.

Krupovic M, Bamford DH. (2007). Putative prophages related to lytic tailless marine dsDNA phage PM2 are widespread in the genomes of aquatic bacteria. $B M C$ Genomics 8: 236-239.

Labonté JM, Suttle CA. (2013). Previously unknown and highly divergent ssDNA viruses populate the oceans. ISME J 7: 2169-2177.

Lang AS, Beatty JT. (2010). Gene transfer agents and defective bacteriophages as sources of extracellular prokaryotic DNA. In: Extracellular Nucleic Acids, Vol. 25, Springer Berlin Heidelberg: Berlin, Germany, pp 15-24.

Lang AS, Zhaxybayeva O, Beatty JT. (2012). Gene transfer agents: phage-like elements of genetic exchange. Nat Rev Microbiol 10: 472-482.

MacDonald IA, Kuehn MJ. (2012). Offense and defense: microbial membrane vesicles play both ways. Res Microbiol 163: 607-618.

MacDonald IA, Kuehn MJ. (2013). Stress-induced outer membrane vesicle production by Pseudomonas aeruginosa. J Bacteriol 195: 2971-2981.

Manning AJ, Kuehn MJ. (2011). Contribution of bacterial outer membrane vesicles to innate bacterial defense. BMC Microbiol 11: 258.

Marie D, Brussaard CPD, Thyrhaug R, Bratbak G, Vaulot D. (1999). Enumeration of marine viruses in culture and natural samples by flow cytometry. Appl Environ Microbiol 65: 45-52.

Martínez Martínez J, Boere A, Gilg I, van Lent J, Witte HJ, van Bleijswijk J et al. (2015). New lipid envelopecontaining dsDNA virus isolates infecting Micromonas pusilla reveal a separate phylogenetic group. Aquat Microb Ecol 74: 17-28.

McBroom AJ, Johnson AP, Vemulapalli S, Kuehn MJ. (2006). Outer membrane vesicle production by Escherichia coli is independent of membrane instability. J Bacteriol 188: 5385-5392.

McDaniel LD, Young E, Delaney J, Ruhnau F, Ritchie KB, Paul JH. (2010). High frequency of horizontal gene transfer in the oceans. Science 330: 50.

Moore L, Coe A, Zinser ER, Saito M, Sullivan M, Lindell D et al. (2007). Culturing the marine cyanobacterium Prochlorococcus. Limnol Oceanogr Methods 5: 353-362.

Noble RT, Fuhrman JA. (1998). Use of SYBR Green I for rapid epifluorescence counts of marine viruses and bacteria. Aquat Microb Ecol 14: 113-118.

Overballe-Petersen S, Harms K, Orlando LAA, Mayar JVM, Rasmussen S, Dahl TW et al. (2013). Bacterial natural transformation by highly fragmented and damaged DNA. Proc Natl Acad Sci USA 110: 19860-19865.

Parsons RJ, Breitbart M, Lomas MW, Carlson CA. (2012). Ocean time-series reveals recurring seasonal patterns of virioplankton dynamics in the northwestern Sargasso Sea. ISME J 6: 273-284.
Patel A, Noble RT, Steele JA, Schwalbach MS, Hewson I, Fuhrman JA. (2007). Virus and prokaryote enumeration from planktonic aquatic environments by epifluorescence microscopy with SYBR Green I. Nat Protoc 2: 269-276.

Pérez-Cruz C, Carrión O, Delgado L, Martinez G, LópezIglesias C, Mercade E. (2013). New type of outer membrane vesicle produced by the Gram-negative bacterium Shewanella vesiculosa M7T: implications for DNA content. Appl Environ Microbiol 79: 1874-1881.

Pérez-Cruz C, Delgado L, López-Iglesias C, Mercade E. (2015). Outer-inner membrane vesicles naturally secreted by Gram-negative pathogenic bacteria. PLoS One 10: e0116896.

Pietilä MK, Roine E, Paulin L, Kalkkinen N, Bamford DH. (2009). An ssDNA virus infecting archaea: a new lineage of viruses with a membrane envelope. Mol Microbiol 72: 307-319.

Poranen MM, Bamford DH, Oksanen HM. (2015). Membranecontaining bacteriophages. eLS; e-pub ahead of print 14 April 2015; doi: 10.1002/9780470015902.a0000440.pub3.

Proctor LM. (1997). Advances in the study of marine viruses. Microsc Res Tech 37: 136-161.

R Core Team. (2015). R: A Language and Environment for Statistical Computing. Available at: https://www.Rproject.org/.

Rath P, Huang C, Wang T, Wang T, Li H, Prados-Rosales R et al. (2013). Genetic regulation of vesiculogenesis and immunomodulation in Mycobacterium tuberculosis. Proc Natl Acad Sci USA 110: E4790-E4797.

Renelli M, Matias V, Lo RY, Beveridge TJ. (2004). DNAcontaining membrane vesicles of Pseudomonas aeruginosa PAO1 and their genetic transformation potential. Microbiology 150: 2161-2169.

Roier S, Zingl FG, Cakar F, Durakovic S, Kohl P, Eichmann TO et al. (2016). A novel mechanism for the biogenesis of outer membrane vesicles in Gram-negative bacteria. Nat Commun 7: 10515.

Rosario K, Schenck RO, Harbeitner RC, Lawler SN, Breitbart M. (2015). Novel circular single-stranded DNA viruses identified in marine invertebrates reveal high sequence diversity and consistent predicted intrinsic disorder patterns within putative structural proteins. Front Microbiol 6: 696.

Roux S, Krupovic M, Debroas D, Forterre P, Enault F. (2013). Assessment of viral community functional potential from viral metagenomes may be hampered by contamination with cellular sequences. Open Biol 3: 130160.

Rumbo C, Fernández-Moreira E, Merino M, Poza M, Mendez JA, Soares NC et al. (2011). Horizontal transfer of the OXA-24 carbapenemase gene via outer membrane vesicles: a new mechanism of dissemination of carbapenem resistance genes in Acinetobacter baumannii. Antimicrob Agents Chemother 55: 3084-3090.

Schertzer JW, Whiteley M. (2012). A bilayer-couple model of bacterial outer membrane vesicle biogenesis. MBio 3: e00297-11.

Schlitzer R. (2016). Ocean Data View. Available at: http:// odv.awi.de.

Schwechheimer C, Kuehn MJ. (2015). Outer-membrane vesicles from Gram-negative bacteria: biogenesis and functions. Nat Rev Microbiol 13: 605-619.

Schwechheimer C, Rodriguez DL, Kuehn MJ. (2015). NlpImediated modulation of outer membrane vesicle production through peptidoglycan dynamics in Escherichia coli. Microbiologyopen 4: 375-389. 
Smith ZJ, Lee C, Rojalin T, Carney RP, Hazari S, Knudson A et al. (2015). Single exosome study reveals subpopulations distributed among cell lines with variability related to membrane content. I Extracell Vesicles 4: 28533.

Soler N, Krupovic M, Marguet E, Forterre P. (2015). Membrane vesicles in natural environments: a major challenge in viral ecology. ISME J 9: 793-796.

Soler N, Marguet E, Verbavatz J-M, Forterre P. (2008). Virus-like vesicles and extracellular DNA produced by hyperthermophilic archaea of the order Thermococcales. Res Microbiol 159: 390-399.

Steward GF, Culley AI, Mueller JA, Wood-Charlson EM, Belcaid M, Poisson G. (2013). Are we missing half of the viruses in the ocean? ISME J 7: 672-679.

Stockner JG, Klut ME, Cochlan WP. (1990). Leaky filters: a warning to aquatic ecologists. Can J Fish Aquat Sci 47: 16-23.

Sullivan MB, Huang KH, Ignacio-Espinoza JC, Berlin AM, Kelly L, Weigele PR et al. (2010). Genomic analysis of oceanic cyanobacterial myoviruses compared with T4-like myoviruses from diverse hosts and environments. Environ Microbiol 12: 3035-3056.

Szekely AJ, Breitbart M. (2016). Single-stranded DNA phages: from early molecular biology tools to recent revolutions in environmental microbiology. FEMS Microbiol Lett 363: fnw027.

Tomaru Y, Nagasaki K. (2007). Flow cytometric detection and enumeration of DNA and RNA viruses infecting marine eukaryotic microalgae. J Oceanogr 63: 215-221.

Toyofuku M, Tashiro Y, Hasegawa Y, Kurosawa M, Nomura N. (2015). Bacterial membrane vesicles, an overlooked environmental colloid: biology, environmental perspectives and applications. Adv Colloid Interface Sci 266: 65-77.
Turnbull L, Toyofuku M, Hynen AL, Kurosawa M, Pessi G, Petty NK et al. (2016). Explosive cell lysis as a mechanism for the biogenesis of bacterial membrane vesicles and biofilms. Nat Commun 7: 11220-13.

Valadi H, Ekström K, Bossios A, Sjöstrand M, Lee JJ, Lötvall JO. (2007). Exosome-mediated transfer of mRNAs and microRNAs is a novel mechanism of genetic exchange between cells. Nat Cell Biol 9: 654-659.

Van Etten JL, Meints RH. (1999). Giant viruses infecting algae. Annu Rev Microbiol 53: 447-494.

Wang Q, Garrity GM, Tiedje JM, Cole JR. (2007). Naive bayesian classifier for rapid assignment of rRNA sequences into the new bacterial taxonomy. Appl Environ Microbiol 73: 5261-5267.

Weinbauer MG, Suttle CA. (1997). Comparison of epifluorescence and transmission electron microscopy for counting viruses in natural marine waters. Aquat Microb Ecol 13: 225-232.

Wickham H. (2009). ggplot2: Elegant Graphics for Data Analysis. Springer: New York, USA.

Wigington CH, Sonderegger D, Brussaard CPD, Buchan A, Finke JF, Fuhrman JA et al. (2016). Re-examination of the relationship between marine virus and microbial cell abundances. Nat Microbiol 1: 15024.

Yaron S, Kolling GL, Simon L, Matthews KR. (2000). Vesicle-mediated transfer of virulence genes from Escherichia coli O157:H7 to other enteric bacteria. Appl Environ Microbiol 66: 4414-4420.

Yáñez-Mó M, Siljander PRM, Andreu Z, Bedina Zavec A, Borràs FE, Buzás EI et al. (2015). Biological properties of extracellular vesicles and their physiological functions. J Extracell Vesicles 4: 27066.

Supplementary Information accompanies this paper on The ISME Journal website (http://www.nature.com/ismej) 